\title{
Amphotericin B resistance of Aspergillus terreus in a murine model of disseminated aspergillosis
}

\author{
E. DANNAOUI, E. BOREL, F. PERSAT, M. A. PIENS and S. PICOT \\ Laboratoire de Parasitologie, Mycologie Médicale et Pathologie Exotique, Université Claude Bernard Lyon I, \\ 8 Avenue Rockefeller, 69373 Lyon Cedex, France
}

\begin{abstract}
The in-vivo activity of amphotericin $B$ and itraconazole against a clinical isolate of Aspergillus terreus was determined in a murine model of disseminated aspergillosis. MICs of amphotericin B and itraconazole for the strain, determined by an NCCLSbased technique, were $2 \mu \mathrm{g} / \mathrm{ml}$ and $1 \mu \mathrm{g} / \mathrm{ml}$, respectively. Mice infected intravenously were treated with either itraconazole $(50$ or $100 \mathrm{mg} / \mathrm{kg} / \mathrm{day})$ or amphotericin $B$ $4.5 \mathrm{mg} / \mathrm{kg} / \mathrm{day}$ for 10 days. Treatment with both doses of itraconazole significantly prolonged the survival rates compared with those for untreated mice. In comparison, mortality rate and median survival time were identical for mice treated with amphotericin $B$ and for mice given no therapy, indicating that the strain was highly resistant to amphotericin $B$ in this model. Analysis of sterol composition showed that the major sterol was ergosterol. This suggests that amphotericin $B$ resistance was not related to a modified sterol profile.
\end{abstract}

\section{Introduction}

The frequency of aspergillus infections has increased in recent years, particularly in patients being treated for haematological malignancies. Among the major species of Aspergillus involved in invasive infections in man, A. fumigatus is the most common, but other species such as $A$. terreus are emerging $[1,2]$. Amphotericin B remains the most established antifungal agent used for the treatment of invasive aspergillosis, even if the overall success rate is low [3]. The antifungal action of amphotericin B originates from its binding to ergoster$\mathrm{ol}$ in the membrane of fungi, altering permeability and causing leakage of cell components [4].

Antifungal susceptibility testing for filamentous fungi is not yet standardised, but different reports have suggested that $A$. terreus is less susceptible to amphotericin $\mathrm{B}$ than $A$. fumigatus in vitro $[5,6]$ and in vivo [2]. Nevertheless, in-vitro detection of amphotericin B resistance of Aspergillus spp. is difficult and correlation of in-vitro results with clinical outcome data is poor $[7,8]$.

Received 28 June 1999; revised version received 21 Dec. 1999; accepted 23 Dec. 1999.

Corresponding author: Dr E. Dannaoui (e-mail: edanna@, rockefeller.univ-lyon1.fr).
Resistance to amphotericin B has often been associated with qualitative or quantitative alterations of membrane lipids, especially sterols [9].

In the present study, a clinical isolate of A. terreus from a patient with invasive pulmonary aspergillosis was tested against amphotericin B and itraconazole in vitro and in vivo in a murine model of aspergillosis and a biochemical study of the sterol composition of this strain was performed.

\section{Materials and methods \\ Strain and patient history}

A. terreus strain AT 81 was isolated from a bronchoalveolar lavage (BAL) fluid from a 54-year-old man with invasive pulmonary aspergillosis who was hospitalised with acute myeloblastic leukaemia. Five weeks after admission, he developed antibiotic-resistant fever and cough, after 30 days of granulocytopenia. Computer tomography scan of his chest showed bilateral nodules with a halo sign. A BAL fluid sample showed hyphae and culture was positive for A. terreus. Circulating Aspergillus antigen (Platelia ${ }^{\circledR}$ Aspergillus, Sanofi Diagnostics Pasteur, Marnes La Coquette, France) was detected in several serum samples. The diagnosis of highly probable pulmonary aspergillosis was established and treatment was started with intravenous amphotericin $\mathrm{B}$ at $1.3 \mathrm{mg} / \mathrm{kg} /$ day and oral 
itraconazole at $600 \mathrm{mg} /$ day. Amphotericin B therapy was given for 7 weeks and itraconazole for 6 months. Itraconazole concentrations in serum were $>1 \mu \mathrm{g} / \mathrm{ml}$, measured by high-performance liquid chromatography (HPLC). One month after therapy was begun, clinical symptoms improved and the lesions remained stable radiographically. The patient died 5 months later from a Stenotrophomonas maltophilia septicaemia.

The A. terreus strain was stored at $-80^{\circ} \mathrm{C}$ in glycerol $10 \%$ until used.

\section{In-vitro susceptibility testing}

Susceptibility testing was performed by an NCCLSbased broth microdilution technique $[10,11]$. RPMI 1640 (Gibco BRL, Uxbridge) with L-glutamine and without sodium bicarbonate, buffered at $\mathrm{pH} 7.0$ with $0.165 \mathrm{M}$ morpholinepropanesulphonic acid (MOPS) was used as the test medium. Amphotericin B (Sigma) and itraconazole (Janssen Pharmaceutica, Beerse, Belgium) were provided by the manufacturers as powders. Both drugs were dissolved in dimethylsulphoxide (DMSO; Sigma) to a concentration of $1600 \mu \mathrm{g} / \mathrm{ml}$ and stored frozen in small volumes at $-80^{\circ} \mathrm{C}$ as stock solutions. The drug dilutions were prepared by following the standard additive two-fold drug dilution scheme described in the NCCLS reference method for yeasts [12], with medium used as the dilutent. The final drug concentrations were $0.03-16 \mu \mathrm{g} / \mathrm{ml}$ for amphotericin B and itraconazole. The strain was cultured on Malt Extract Agar (MEA) slants (Sanofi Diagnostics Pasteur) at $35^{\circ} \mathrm{C}$ for 5 days. The inoculum was prepared by washing the surface of the agar slants with $1 \mathrm{ml}$ of sterile $\mathrm{NaCl} \quad 0.9 \%$ containing Tween $800.05 \%$. The resulting conidial suspension was counted with a haemocytometer. Sterile 96-well U-shaped microtitration plates were used. The conidia were diluted in RPMI and each well of rows 212 was inoculated. The final inoculum concentration was $1 \times 10^{4}$ conidia $/ \mathrm{ml}$. Row 1 was used as sterility control and row 12 as growth control. The MICs were run in duplicate. Microtitration plates were incubated at $35^{\circ} \mathrm{C}$ for $48 \mathrm{~h}$ and the growth in each well was compared with that of the growth control with the aid of a microtitre reading mirror. Each well was then given a numerical score [10]: 4, no reduction in growth; 3, growth reduction of $25 \% ; 2$, growth reduction of $50 \%$; 1 , growth reduction of $\geqslant 75 \%$; and 0 , absence of growth (optically clear). MIC endpoints were defined as the lowest drug concentration which had a score of 1 for itraconazole and the lowest concentration that had a score of 0 for amphotericin B.

\section{Mice}

Female OF-1 outbred mice (IFFA CREDO, 1'Arbresle, France), 5-7 weeks old, weighing 20-22 g were used throughout the experiments. Mice were housed in groups of 10 and were given food and water ad libitum. Animal studies were conducted in accordance with the recommendations of the European Communities (Directive no. 86/609/EEC, 24 November 1986).

\section{Infection}

The inoculum was prepared by culturing the strain on MEA for 5 days at $35^{\circ} \mathrm{C}$. Spores were harvested by washing the agar slant with sterile $\mathrm{NaCl} \quad 0.9 \%$ containing Tween $800.05 \%$ and the spore suspension was counted in a haemocytometer. Viability was determined by plating serial 10 -fold dilutions prepared in $\mathrm{NaCl} 0.9 \%$ with Tween $800.05 \%$. Plates were incubated at $35^{\circ} \mathrm{C}$ and the numbers of cfu were counted at $24 \mathrm{~h}$ and $48 \mathrm{~h}$. On the day of infection, the spore suspension was adjusted to the required concentration in $\mathrm{NaCl} 0.9 \%$. A preliminary study was performed to determine the LD90 (90\% lethal dose) for the strain by testing three inoculum sizes $\left(1 \times 10^{5}, 1 \times 10^{6}\right.$ and $1 \times 10^{7} \mathrm{cfu} /$ mouse). Mice were infected by injection of $0.1 \mathrm{ml}$ of the conidial suspension into a lateral tail vein. After infection, mice were randomised to the different treatment groups.

\section{Drugs and therapy}

Amphotericin B desoxycholate (Fungizone ${ }^{\circledR}$; BristolMyers Squibb, Paris, France) was given in glucose 5\% intraperitoneally (i.p.) and itraconazole (Sporanox ${ }^{\circledR}$ oral solution; Janssen Pharmaceutica, Beerse, Belgium) was diluted in sterile water and given by gavage. Treatment with both drugs was begun $2 \mathrm{~h}$ after infection and was continued for 10 days. Five groups of 10 mice were used. One group was treated with amphotericin B $4.5 \mathrm{mg} / \mathrm{kg} /$ day by once-daily injection and two groups were treated with itraconazole $100 \mathrm{mg} / \mathrm{kg} /$ day and $50 \mathrm{mg} / \mathrm{kg} /$ day, respectively, administered in two daily doses. Control mice were infected, but received only glucose $5 \%$, one group by intraperitoneal injection and one group by gavage. Animals were checked twice daily for mortality. The mice were observed for 12 days after the end of treatment.

\section{Organ cultures}

Surviving mice on day 22 after infection were killed by cervical dislocation and quantitative cultures of brain and kidney were performed. Organs were removed and homogenised with $3 \mathrm{ml}$ of $\mathrm{NaCl} 0.9 \%$ in a tissue grinder. Two 10-fold serial dilutions were made and $0.1 \mathrm{ml}$ of each dilution (including the neat dilution) was plated on to Sabouraud's agar. Plates were incubated at $35^{\circ} \mathrm{C}$ and colonies were counted daily for 3 days for control groups and 5 days for treated groups. Qualitative organ cultures were performed on all mice that died before the end of the experiment. 


\section{Itraconazole assay}

Two groups of six uninfected mice were given itraconazole by gavage at $50 \mathrm{mg} / \mathrm{kg} /$ day and 100 $\mathrm{mg} / \mathrm{kg} /$ day, respectively. In each group, three mice were killed after 4 days of treatment and three after 6 days of treatment, $6 \mathrm{~h}$ after the last dose was administered. Blood was obtained by cardiac puncture and organs (kidney and brain) were homogenised in a tissue grinder with $3 \mathrm{ml}$ of $\mathrm{NaCl} 0.9 \%$. Serum and tissue levels of itraconazole were determined by HPLC $[13,14]$.

\section{Sterol analysis}

For sterol analysis, the strain was cultured on MEA for 5 days at $35^{\circ} \mathrm{C}$. Spores were harvested and $100 \mathrm{ml}$ of Sabouraud liquid medium (Sanofi Diagnostics Pasteur) were inoculated with $5 \times 10^{5}$ conidia $/ \mathrm{ml}$ and the strain was grown for $24 \mathrm{~h}$ at $35^{\circ} \mathrm{C}$ with agitation. Mycelium $\left(500 \mathrm{mg}\right.$ ) was saponified at $80^{\circ} \mathrm{C}$ for $2 \mathrm{~h}$ with $3 \mathrm{ml}$ of methanol, $2 \mathrm{ml}$ of pyrogallol $0.5 \%$ in methanol, and $2 \mathrm{ml}$ of aqueous $\mathrm{KOH} 60 \%$. The non-saponifiable lipids (sterols) were then extracted three times with $5 \mathrm{ml}$ of hexane. After the hexane had been evaporated under nitrogen, samples were stored at $-20^{\circ} \mathrm{C}$ before use. Sterols were analysed under trimethylsilyl ether derivatives by gas chromatography-mass spectrometry on an HP 5970 apparatus. The capillary column $(30 \mathrm{~m} \times 0.25 \mathrm{~mm})$ was coated with DB-XLB (J. W. Scientific, Folsom, CA, USA). Injection (1-2 $\mu \mathrm{l})$ was via a splitless injector at $280^{\circ} \mathrm{C}$ and the carrier gas was helium at $100 \mathrm{kPa}$. The oven temperature was set at $200^{\circ} \mathrm{C}$ for $1 \mathrm{~min}$, then raised from 200 to $260^{\circ} \mathrm{C}$ at $8^{\circ} \mathrm{C} / \mathrm{min}$ and from 260 to $320^{\circ} \mathrm{C}$ at $2^{\circ} \mathrm{C} / \mathrm{min}$. Electronic impact spectra were obtained at $70 \mathrm{eV}$. The sterols were quantified by electronic integration of chromatogram peaks, and results are expressed as percent area. Identification was made by comparison of their fragmentation data with controls and published data [15-17].

\section{Data analysis}

Data for the two control groups were pooled for the analysis. Mortality and quantitative culture data were compared by the Kruskal-Wallis test $(p<0.05$ was considered significant). Organs from mice that died before the end of the experiment were assigned quantitative values equal to the highest counts in the organs of any surviving mouse, assuming that death represented a worse outcome than survival with any fungal organ burden. Qualitative organ cultures were compared by the Fisher's exact test $(p<0.01$ was considered significant).

\section{Results}

In-vitro susceptibility testing was performed three times with reproducible results. The MICs of the $A$. terreus strain obtained from the patient BAL, determined by an NCCLS-based technique, were $2 \mu \mathrm{g} / \mathrm{ml}$ for amphotericin B and $1 \mu \mathrm{g} / \mathrm{ml}$ for itraconazole.

For the animal model, a preliminary experiment was performed to determine the LD90 of the strain at day 11 (which corresponded to the end of the treatment period in the treatment experiment). Survival rates of mice infected with three different inoculum sizes were determined. Mortality rates were 10, 40 and $80 \%$ for $1 \times 10^{5}, 1 \times 10^{6}$ and $1 \times 10^{7} \mathrm{cfu} /$ mouse, respectively. The LD90 was estimated at $2 \times 10^{7} \mathrm{cfu} /$ mouse and this inoculum size was used for the treatment experiment.

Fig. 1 shows the survival curve for the treatment experiment and median survival time are shown in Table 1 . In the control groups, $100 \%$ of mice receiving glucose i.p. died and $90 \%$ died in the group receiving glucose by gavage. Treatment with itraconazole at $50 \mathrm{mg} / \mathrm{kg} /$ day and $100 \mathrm{mg} / \mathrm{kg} /$ day resulted in a $70 \%$ and $90 \%$ survival rate, respectively; significantly better than for mice receiving no treatment $(p<0.001)$. In comparison, mice treated with amphotericin B died within 12 days, which was not significantly different from control groups $(\mathrm{p}>0.05)$.

Concentrations of itraconazole in serum and in kidney and brain are presented in Table 2. In serum, itraconazole levels were $1.7-2.5$-fold higher in the group treated with $100 \mathrm{mg} / \mathrm{kg} /$ day than in the group treated with $50 \mathrm{mg} / \mathrm{kg} /$ day. Serum levels were in same range at day 4 and day 6. Concentrations of itraconazole in organs (kidney and brain) were determined only in mice receiving $100 \mathrm{mg} / \mathrm{kg} /$ day. In kidney, the level of itraconazole was c. $60 \%$ that of the level in plasma at day 4 and was 2.6 times higher at day 6 . In brain, levels were in the same range at day 4 and day 6 , but were lower than those detected in kidney and serum.

Qualitative culture results of kidney and brain for all mice are presented in Table 3 and quantitative fungal burdens are shown in Table 4. All control mice had positive kidney and brain cultures. Identical results were found in the amphotericin B group. Itraconazole therapy at dosages of both 50 and $100 \mathrm{mg} / \mathrm{kg} /$ day did not reduce kidney infections. Brain cultures were positive in $80 \%$ of the cases in the group given itraconazole at $100 \mathrm{mg} / \mathrm{kg} /$ day and in $67 \%$ in the group given itraconazole at $50 \mathrm{mg} / \mathrm{kg} /$ day. As shown in Table 4, amphotericin B did not reduce fungal burdens in kidney and brain compared with controls. Itraconazole therapy at 50 and $100 \mathrm{mg} / \mathrm{kg} /$ day significantly reduced colony counts in kidney and brain and appeared to act in a dose-dependent manner.

The relative sterol composition of the strain is shown in Table 5. Ergosterol was the major sterol detected, representing $>85 \%$ of the total amount of sterols. 24- 


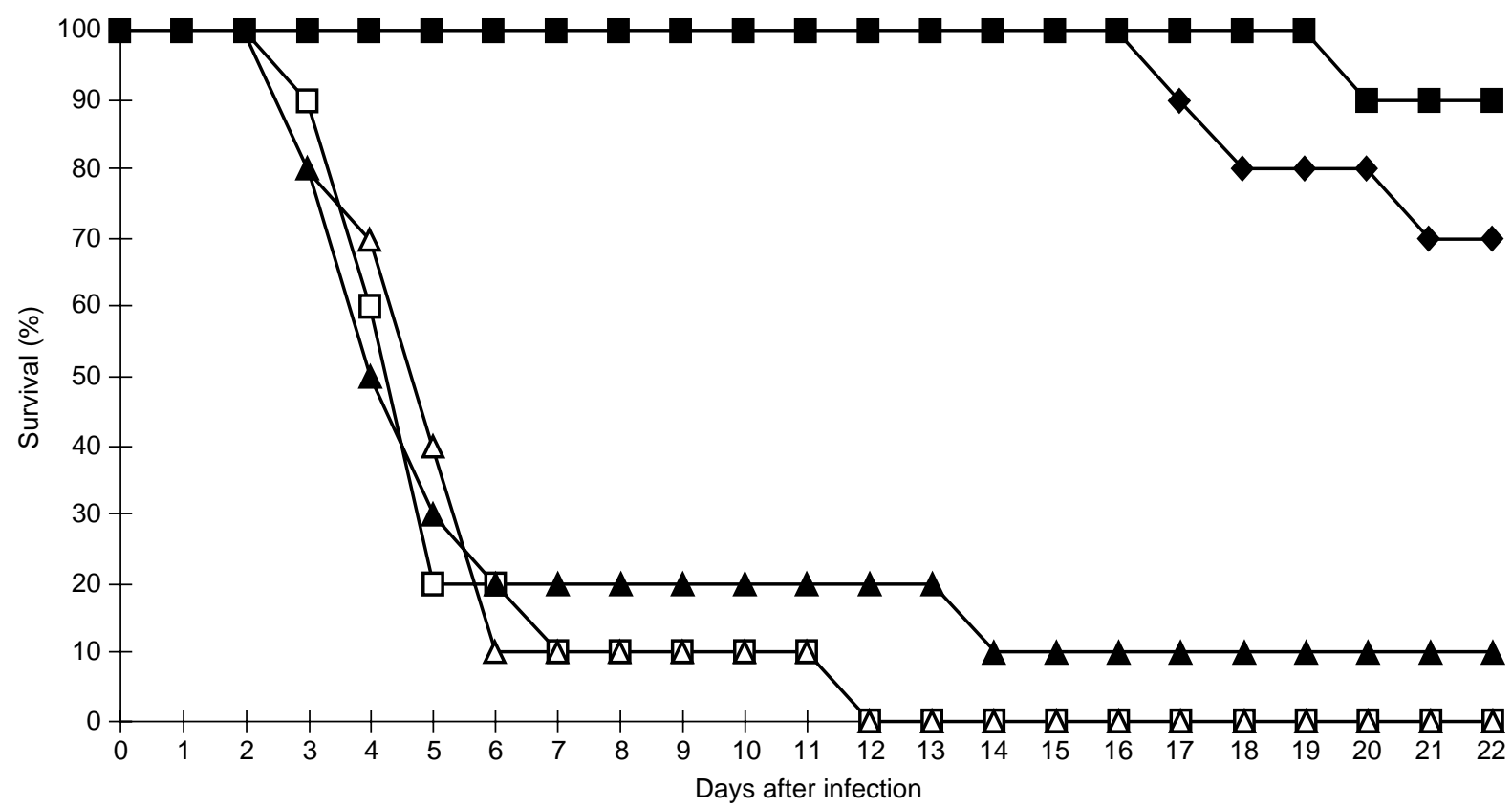

Fig. 1. Cumulative mortality for mice infected with A. terreus AT 81 in treated and control groups. $\mathbf{\square}$, itraconazole $100 \mathrm{mg} / \mathrm{kg} /$ day; $\diamond$, itraconazole $50 \mathrm{mg} / \mathrm{kg} /$ day; $\square$, amphotericin B $4.5 \mathrm{mg} / \mathrm{kg} /$ day; $\boldsymbol{\Delta}, 5 \%$ glucose control (by gavage); $\triangle, 5 \%$ glucose control (i.p.).

Table 1. Survival times for mice infected with A. terreus AT 81 and treated with amphotericin B $(4.5 \mathrm{mg} / \mathrm{kg} /$ day $)$ or itraconazole $(100$ or $50 \mathrm{mg} / \mathrm{kg} /$ day $)$

\begin{tabular}{lcc}
\hline Group & $\begin{array}{c}\text { Number of } \\
\text { survivors/number of } \\
\text { mice in group }\end{array}$ & $\begin{array}{c}\text { Median survival time } \\
\text { (days) and range }\end{array}$ \\
\hline Controls & $1 / 20$ & $5(3-23)$ \\
Amphotericin B & $0 / 10$ & $5(3-12)$ \\
Itraconazole $100 \mathrm{mg}$ & $9 / 10$ & $23^{*}(20-23)$ \\
Itraconazole $50 \mathrm{mg}$ & $7 / 10$ & $23^{*}(17-23)$ \\
\hline
\end{tabular}

${ }^{*} \mathrm{p}<0.001$ (compared with controls).

Table 2. Serum and tissue levels of itraconazole (native plus hydroxylated itraconazole) in mice after treatment for 4 days and 6 days with itraconazole at 100 or $50 \mathrm{mg} / \mathrm{kg} /$ day

\begin{tabular}{lccc}
\hline & \multicolumn{3}{c}{ Mean (SD) level in * } \\
\cline { 2 - 4 } Group & serum $(\mu \mathrm{g} / \mathrm{ml})$ & kidney $(\mu \mathrm{g} / \mathrm{g})$ & brain $(\mu \mathrm{g} / \mathrm{g})$ \\
\hline Day 4 & $7.09(1.52)$ & $4.55(1.38)$ & $1.33(0.40)$ \\
$\quad$ Itraconazole $100 \mathrm{mg}$ & $4.05(0.53)$ & $\mathrm{ND}$ & $\mathrm{ND}$ \\
Itraconazole $50 \mathrm{mg}$ & $8.24(0.51)$ & $11.82(1.20)$ & $1.81(0.69)$ \\
Day 6 & $3.32(0.93)$ & $\mathrm{ND}$ & $\mathrm{ND}$ \\
$\quad$ Itraconazole $100 \mathrm{mg}$ & & & \\
Itraconazole $50 \mathrm{mg}$ & &
\end{tabular}

ND, not determined.

* Three mice in each group.

Table 3. Qualitative culture results for kidney and brain for all mice

\begin{tabular}{lcc}
\hline & $\begin{array}{c}\text { Number of mice positive/number of } \\
\text { mice in group }\end{array}$ \\
\cline { 2 - 3 } Group & kidneys & brains \\
\hline Controls & $20 / 20$ & $20 / 20$ \\
Amphotericin B & $10 / 10$ & $10 / 10$ \\
Itraconazole 100 mg & $10 / 10$ & $8 / 10$ \\
Itraconazole 50 mg & $10 / 10$ & $6 / 9^{*}$ \\
\hline
\end{tabular}

*Brain from one mouse was not cultured.
Ethyl-cholesta-5,7,22-trienol, previously characterised in zygomycetes [18], was also detected (c. $10 \%$ of the total amount of sterols). Each fraction of other biosynthetic intermediates was $<2 \%$.

\section{Discussion}

The present study demonstrated amphotericin B resistance in a strain of $A$. terreus in an animal model of aspergillosis. 
Table 4. Quantitative culture results for kidney and brain

\begin{tabular}{|c|c|c|c|c|}
\hline \multirow[b]{2}{*}{ Strain and treatment group } & \multirow{2}{*}{$\begin{array}{l}\text { Number } \\
\text { of mice } \\
\text { in group }\end{array}$} & \multirow{2}{*}{$\begin{array}{c}\text { Number of } \\
\text { survivors }\end{array}$} & \multicolumn{2}{|c|}{ Mean $(\mathrm{SD}) \mathrm{cfu} \times 10^{2} / \mathrm{g}$ in } \\
\hline & & & kidney & brain \\
\hline Controls & 20 & 1 & $11609(0)$ & $33.9 \quad(7.2)$ \\
\hline Amphotericin B & 10 & 0 & $11609(0)$ & $35.5 \quad(0)$ \\
\hline Itraconazole $100 \mathrm{mg}$ & 10 & 9 & $1219^{*}(3652)$ & $10.8^{\dagger}(16)$ \\
\hline Itraconazole $50 \mathrm{mg}$ & 10 & 7 & $3894^{*}(5423)$ & $12.1^{*}(16.4)$ \\
\hline
\end{tabular}

${ }^{*} \mathrm{p}<0.001 ;{ }^{\dagger} \mathrm{p}<0.01 ;{ }^{\dagger} \mathrm{p}<0.05$ (compared with controls).

Table 5. Relative sterol composition of A. terreus AT 81 mycelium grown for $24 \mathrm{~h}$ without antifungal agents

\begin{tabular}{lc}
\hline Sterol & Percentage of total sterol \\
\hline Ergosterol & 85.2 \\
24-Ethyl-cholesta-5,7,22-trienol & 10.1 \\
Episterol & 1.5 \\
Ergosta 5,8,22,trienol & 1.4 \\
Unknown sterols & 1.8 \\
\hline
\end{tabular}

Technical procedures for the in-vitro susceptibility testing of Aspergillus spp. are currently not standardised and numerous methods have been applied, with very different results [19]. Nevertheless, large-scale collaborative inter-laboratory studies have shown that adaptation of the NCCLS standard method for susceptibility testing of yeasts [12] is reproducible and reliable for the in-vitro determination of the antifungal susceptibility of filamentous fungi $[10,11]$. The present study used an NCCLS-based technique to determine MICs of itraconazole and amphotericin B. The MIC of the $A$. terreus AT 81 was $\leqslant 2 \mu \mathrm{g} / \mathrm{ml}$ against both drugs. Nevertheless, amphotericin B resistance of Aspergillus spp. is difficult to detect in vitro and correlation between MIC and outcome of treatment with amphotericin B is poor [7, 8]. For this reason, an animal model of aspergillosis was used to test the amphotericin B resistance of $A$. terreus. This model of disseminated aspergillosis in immunocompetent mice has been used previously to confirm in-vitro resistance to itraconazole in A. fumigatus strains [20]. In the present study, the strain of $A$. terreus was shown to be highly resistant to amphotericin B. The low MIC of the strain against itraconazole and the good activity of itraconazole therapy in prolonging survival and reducing colony counts in both brain and kidney of infected mice demonstrate that there was no cross-resistance between amphotericin $\mathrm{B}$ and itraconazole. In the case reported here, itraconazole was given concurrently with amphotericin B and the patient showed a clinical improvement, which is consistent with a previous report [21].

The antifungal action of amphotericin B originates from its binding to ergosterol, leading to the formation of transmembrane channels, which induce altered permeability and cause leakage of cell components [4]. Moreover, it has been shown that oxidative damage plays a role in the mechanism of fungal cell killing by amphotericin B [22]. The analysis of sterol composition of strain AT 81 showed an ergosterol content of $85 \%$. A similar ergosterol content has been described in a strain of A. fumigatus which is susceptible to amphotericin $\mathrm{B}$ in vivo $[23,24]$. Polyene antifungal resistance has previously been attributed to lesions in the ergosterol biosynthetic pathway in clinical isolates of Candida albicans [22,25,26] and Cryptococcus neoformans [27] and in laboratory mutants of $C$. albicans [22, 28], A. fennelliae [29] and of a protozoan, Leishmania donovani [30]. Nevertheless, amphotericin B resistance has also been reported in $C$. albicans [31], Cr. neoformans [32,33] and Ustilago maydis [34] without significant alterations in sterol biosynthesis. In these cases, the underlying mechanism of such resistance remains unclear.

In conclusion, this study demonstrated the in-vivo resistance of a clinical isolate of $A$. terreus to amphotericin B. Biochemical studies suggest that the resistance is not related to a lack of ergosterol. Further studies are needed to confirm these results in other strains of A. terreus and to define the mechanism of amphotericin B resistance.

This study was supported by a grant from Hospices Civils de Lyon, France. We are indebted to Marie-France Monier for technical assistance and to Aline Farille and Lucette Villard for their invaluable help. We thank Michel Becchi from the Laboratoire de Spectrométrie de Masse, Service Central d'Analyse du CNRS, Solaize (France) for $\mathrm{GC} / \mathrm{MS}$ analyses.

\section{References}

1. Iwen PC, Rupp ME, Langnas AN, Reed EC, Hinrichs SH. Invasive pulmonary aspergillosis due to Aspergillus terreus: 12-year experience and review of the literature. Clin Infect Dis 1998; 26: 1092-1097.

2. Lass-Flörl C, Kofler G, Kropshofer G et al. In-vitro testing of susceptibility to amphotericin B is a reliable predictor of clinical outcome in invasive aspergillosis. $J$ Antimicrob Chemother 1998; 42: 497-502.

3. Denning DW. Invasive aspergillosis. Clin Infect Dis 1998; 26: 781-803.

4. Brajtburg J, Powderly WG, Kobayashi GS, Medoff G. Amphotericin B: current understanding of mechanisms of action. Antimicrob Agents Chemother 1990; 34: 183-188.

5. Dannaoui E, Persat F, Monier M-F, Borel E, Piens M-A, Picot S. In-vitro susceptibility of Aspergillus spp. isolates to amphotericin B and itraconazole. J Antimicrob Chemother 1999; 44: 553-555.

6. Oakley KL, Moore CB, Denning DW. Comparison of in vitro activity of liposomal nystatin against Aspergillus species with those of nystatin, amphotericin $\mathrm{B}$ (AB) deoxycholate, $\mathrm{AB}$ colloidal dispersion, liposomal $\mathrm{AB}, \mathrm{AB}$ lipid complex, and 
itraconazole. Antimicrob Agents Chemother 1999; 43: 1264-1266.

7. Verweij PE, Oakley KL, Morrissey J, Morrissey G, Denning DW. Efficacy of LY303366 against amphotericin B-susceptible and -resistant Aspergillus fumigatus in a murine model of invasive aspergillosis. Antimicrob Agents Chemother 1998; 42 : $873-878$.

8. Odds FC, Van Gerven F, Espinel-Ingroff A et al. Evaluation of possible correlations between antifungal susceptibilities of filamentous fungi in vitro and antifungal treatment outcomes in animal infection models. Antimicrob Agents Chemother 1998; 42: 282-288.

9. Vanden Bossche H, Dromer F, Improvisi I, Lozano-Chin M, Rex JH, Sanglard D. Antifungal drug resistance in pathogenic fungi. Med Mycol 1998; 36 Suppl 1: 119-128.

10. Espinel-Ingroff A, Dawson K, Pfaller M et al. Comparative and collaborative evaluation of standardization of antifungal susceptibility testing for filamentous fungi. Antimicrob Agents Chemother 1995; 39: 314-319.

11. Espinel-Ingroff A, Bartlett $\mathrm{M}$, Bowden $\mathrm{R}$ et al. Multicenter evaluation of proposed standardized procedure for antifungal susceptibility testing of filamentous fungi. J Clin Microbiol 1997; 35: 139-143

12. NCCLS. Reference method for broth dilution antifungal susceptibility testing of yeasts. M-27A. Villanova, PA, National Committee for Clinical Laboratory Standards. 1995.

13. Michallet M, Persat F, Kranzhofer N et al. Pharmacokinetics of itraconazole oral solution in allogeneic bone marrow transplant patients receiving total body irradiation. Bone Marrow Transplant 1998; 21: 1239-1243.

14. Warnock DW, Turner A, Burke J. Comparison of high performance liquid chromatographic and microbiological methods for determination of itraconazole. J Antimicrob Chemother 1988; 21: 93-100.

15. Quail MA, Arnoldi A, Moore DJ, Goosey MW, Kelly SL. Ketoconazole-mediated growth inhibition in Botrytis cinerea and Saccharomyces cerevisiae. Phytochemistry 1993; 32: 273-280.

16. Loeffler RST, Hayes AL. Effects of sterol biosynthesis inhibitor fungicides on growth and sterol composition of Ustilago maydis, Botrytis cinerea and Pyrenophora teres. Pestic Sci 1992; 36: 7-17.

17. Loeffler RST, Hayes L. Sterols of the plant pathogenic fungi Botrytis cinerea and Pyrenophora teres. Phytochemistry 1990; 29: $3423-3425$.

18. Weete JD, Gandhi SR. Sterols of the phylum zygomycota: phylogenetic implications. Lipids 1997; 32: 1309-1316.

19. Denning DW, Hanson LH, Perlman AM, Stevens DA. In vitro susceptibility and synergy studies of Aspergillus species to conventional and new agents. Diagn Microbiol Infect Dis 1992; 15: $21-34$.

20. Dannaoui E, Borel E, Persat F, Monier MF, Piens MA and EBGA Network. In-vivo itraconazole resistance of Aspergillus fumigatus in systemic murine aspergillosis. J Med Microbiol 1999; 48: 1087-1093.

21. Denning DW, Marinus A, Cohen J et al. An EORTC multicentre prospective survey of invasive aspergillosis in haematological patients: diagnosis and therapeutic outcome. $J$ Infect 1998; 37: 173-180.

22. Sokol-Anderson M, Sligh JE, Elberg S, Brajtburg J, Kobayashi GS, Medoff G. Role of cell defense against oxidative damage in the resistance of Candida albicans to the killing effect of amphotericin B. Antimicrob Agents Chemother 1988; 32: 702-705

23. Denning DW, Radford SA, Oakley KL, Hall L, Johnson EM, Warnock DW. Correlation between in-vitro susceptibility testing to itraconazole and in-vivo outcome of Aspergillus fumigatus infection. $J$ Antimicrob Chemother 1997; 40: 401-414.

24. Denning DW, Venkateswarlu K, Oakley KL et al. Itraconazole resistance in Aspergillus fumigatus. Antimicrob Agents Chemother 1997; 41: 1364-1368.

25. Kelly SL, Lamb DC, Kelly DE, Loeffler J, Einsele H. Resistance to fluconazole and amphotericin in Candida albicans from AIDS patients. Lancet 1996; 348: $1523-1524$.

26. Nolte FS, Parkinson T, Falconer DJ et al. Isolation and characterization of fluconazole- and amphotericin B-resistant Candida albicans from blood of two patients with leukemia. Antimicrob Agents Chemother 1997; 41: 196-199.

27. Kelly SL, Lamb DC, Taylor M. Corran AJ, Baldwin BC, Powderly WG. Resistance to amphotericin B associated with defective sterol $\Delta 8 \rightarrow 7$ isomerase in a Cryptococcus neoformans strain from an AIDS patient. FEMS Microbiol Lett 1994; 122: 39-42.

28. Hitchcock CA, Barrett-Bee KJ, Russell NJ. The lipid composition and permeability to azole of an azole- and polyene-resistant mutant of Candida albicans. J Med Vet Mycol 1987; 25: 29-37.

29. Kim SJ, Kwon-Chung KJ, Milne GWA, Prescott B. Polyeneresistant mutants of Aspergillus fennelliae: identification of sterols. Antimicrob Agents Chemother 1974; 6: 405-410.

30. Mbongo N, Loiseau PM, Billion MA, Robert-Gero M. Mechanism of amphotericin B resistance in Leishmania donovani promastigotes. Antimicrob Agents Chemother 1998; 42: 352-357.

31. Broughton MC, Bard M, Lees ND. Polyene resistance in ergosterol producing strains of Candida albicans. Mycoses 1991; 34: 75-83.

32. Currie B, Sanati H, Ibrahim AS, Edwards JE, Casadevall A, Ghannoum MA. Sterol compositions and susceptibilities to amphotericin B of environmental Cryptococcus neoformans isolates are changed by murine passage. Antimicrob Agents Chemother 1995; 39: 1934-1937.

33. Joseph-Horne T, Loeffler RS, Hollomon DW, Kelly SL. Amphotericin B resistant isolates of Cryptococcus neoformans without alteration in sterol biosynthesis. $J$ Med Vet Mycol 1996; 34: 223-225.

34. Joseph-Horne T, Manning N, Holoman D, Kelly S. Nonsterol related resistance in Ustilago maydis to the polyene antifungals, amphotericin B and nystatin. Phytochemistry 1996; 42: 637-639. 